\title{
Analysis of Cost Performance Indicators in Reconstruction Projects: A Comparative Study of Low vs High Level Damages
}

\author{
Elnaz Safapour ${ }^{1}$, Sharareh Kermanshachi ${ }^{2}$ and Thahomina Jahan Nipa ${ }^{3}$
}

1 Department of Civil Engineering, University of Texas at Arlington, Arlington, USA, elnaz.safapour@mavs.uta.edu

2 Department of Civil Engineering, University of Texas at Arlington, Arlington, USA, sharareh.kermanshachi@uta.edu

3 Department of Civil Engineering, University of Texas at Arlington, Arlington, USA, thahomina.nipa@mavs.uta.edu

\begin{abstract}
With the increase in frequency and intensity of natural disasters, the number of transportation infrastructures needing reconstruction is also increasing. Insufficient financial resources and cost overruns are among the major limitations that affect the reconstruction works of the transportation infrastructure after a disaster; however, there are few resources to help practitioners monitor the cost of reconstruction and keep it within the allocated budget. This study aims to provide a comprehensive list of the critical factors that affect the reconstruction cost (CFRC) of transportation infrastructures after a disaster, and to categorize them, based on the level of damage incurred. A survey was conducted to determine the importance of 30 potential CFRCs, and the survey results were statistically analyzed. It was found that effective coordination plays a critical role in completing a project within the budget limitations, a slow decision-making process slows the reconstruction efforts and increases the probability of cost overruns, and the reconstruction cost of transportation infrastructures with a high level of damage are dependent on more factors than infrastructures with a low level of damage. For example, when the damage level is low, fewer disruptions to traffic are necessary during the reconstruction than if the damage level is high. When the damage level is high, the likelihood of more traffic disturbance is greater, which has the potential to create unforeseen costs and/or cost overruns. The outcome of this paper will be of value to the authorities who are responsible for controlling budget overruns during post-disaster reconstruction projects.
\end{abstract}

(C) 2020 The Authors. Published by Budapest University of Technology and Economics \& Diamond Congress Ltd Peer-review under responsibility of the Scientific Committee of the Creative Construction Conference 2020.

Keywords: maximum five keywords, in lower case, alphabetical order, separated by commas, finishing with full-stop

\section{Introduction}

Natural disasters are one of the major causes of losses and casualties worldwide [1, 2, 3], and hurricanes are among the most powerful and destructive disasters [4]. The destruction wreaked by Hurricane Katrina in 2005 was estimated at more than $\$ 160$ billion [5], Hurricane lke left massive destruction in its wake in 2005 [6], and Hurricane Harvey destroyed a considerable number of structures when it hit the southern part of Texas in 2017 [7].

Since the number of natural disasters, especially hurricanes, has increased over the last two decades $[8,9]$ limited financial resources have become a critical factor that seriously affects the success of post-hurricane reconstruction projects [10,11,12,13]. Hidayat and Egbu [14] and Chang et al. [15] explained it by saying that inflated prices and/or shortages of laborers, materials, and equipment commonly occur after hurricanes and lead to cost overruns, schedule delays, and even failure of reconstruction projects. [16, 17, 
18, 19]. Few studies have been conducted to estimate the cost and/or duration of post-hurricane reconstruction of transportation infrastructures to prevent cost overruns and time delays in projects, but the project's cost is usually considered an indicator of the duration of the construction phase [20, 21].

Reconstruction after a disaster comes with the notion of building back better, with resiliency against future disasters, which increases the reconstruction costs even more $[22,23]$. One of the best strategies for completing a reconstruction project within budget is to identify the factors that affect its cost [24, 25]; however, few studies have investigated these factors and limited literature is available on the subject. In addition, not all disasters damage transportation infrastructures at the same level [26], which means that the resources and financial needs are different for the various levels of damage. For example, [13] found that floods damage transportation infrastructures more than fires or storms; therefore, the financial and resource outlay will be greater after a flood. Hence, it is necessary to investigate the factors that affect the cost of reconstruction based on the level of damage.

This research aims to fill the above-mentioned gaps by identifying and classifying the critical factors affecting reconstruction costs (CFRC) of transportation infrastructures after a disaster. To achieve the aim of this study, the following objectives were formulated: i) identify the potential CFRCs that affect the reconstruction cost, ii) determine the significant CFRCs that affect reconstruction cost, and iii) classify the CFRCs based on the level of damage. The outcome of this paper will be of value to the authorities who are responsible for controlling budget overruns during post-disaster reconstruction projects.

\section{Literature review}

In the last three decades, the number of natural disasters has increased significantly, and with that increase has come a strong disruption of the functioning of society, as serious human and environmental impacts are experienced when an affected community cannot cope with the loss of their resources [27, 28]. Natural disasters cause physical and psychological trauma to society and damage to the environment $[25,29]$. Furthermore, the losses and damages experienced have not increased proportionally, as they increased from approximately $\$ 10$ billion in 1975 to approximately $\$ 90$ billion in 2009 [27].

The transportation sector experiences some of the greatest losses and damages from a disaster [27]; however, its reconstruction provides an often unrecognized advantage to the affected community, as several studies have shown that the reconstruction of the transportation sector accelerates the process of recovery in all of the affected areas [30]. It is a continuous procedure that needs to begin immediately after the disaster and often takes longer to complete than what was estimated [31, 32]. Multiple researchers and authors have espoused that cost overruns are one of the most serious issues and challenges that governments face in construction and reconstruction projects $[33,34,35,36]$ as a result of the complexity of the projects $[37,38]$.

Every post-hurricane reconstruction project is unique, and the differences can be those of safety and environmental issues or even the attitudes of the decision-makers [39, 40]. Multiple studies have been conducted to identify the root causes of post-disaster reconstruction projects' success and failure [41], and Table 1 depicts the causes of cost overruns and failure.

Table 1. Challenges creating cost overruns of the reconstruction of the transportation infrastructure after a disaster

\begin{tabular}{lc}
\hline \multicolumn{1}{c}{ Challenge } & Previous Study \\
\hline Finance and limitation of funds & {$[9]$} \\
\hline Ineffective design & {$[22]$} \\
\hline Inadequacy of resource procurement & {$[11]$} \\
\hline Unavailability of human resources & {$[23]$} \\
\hline Unavailability of material resources & {$[23]$} \\
\hline Engineering mobilization & {$[24]$} \\
\hline Inflation & {$[11]$} \\
\hline
\end{tabular}




\section{Research methodology}

\subsection{Outline}

A structured research framework was designed to fulfil the goals of this research. Figure 1 shows that a comprehensive review was performed of the existing literature to identify potential CFRCs affecting projects' costs. Over 200 journal articles, conference papers, dissertations, and research reports were identified from five main databases, Google Scholar, JSTOR, ProQuest, and Science Direct. More than 75\% of all the articles were peer-reviewed journal articles. The articles were carefully reviewed, and the most relevant articles were included; the others were discarded.

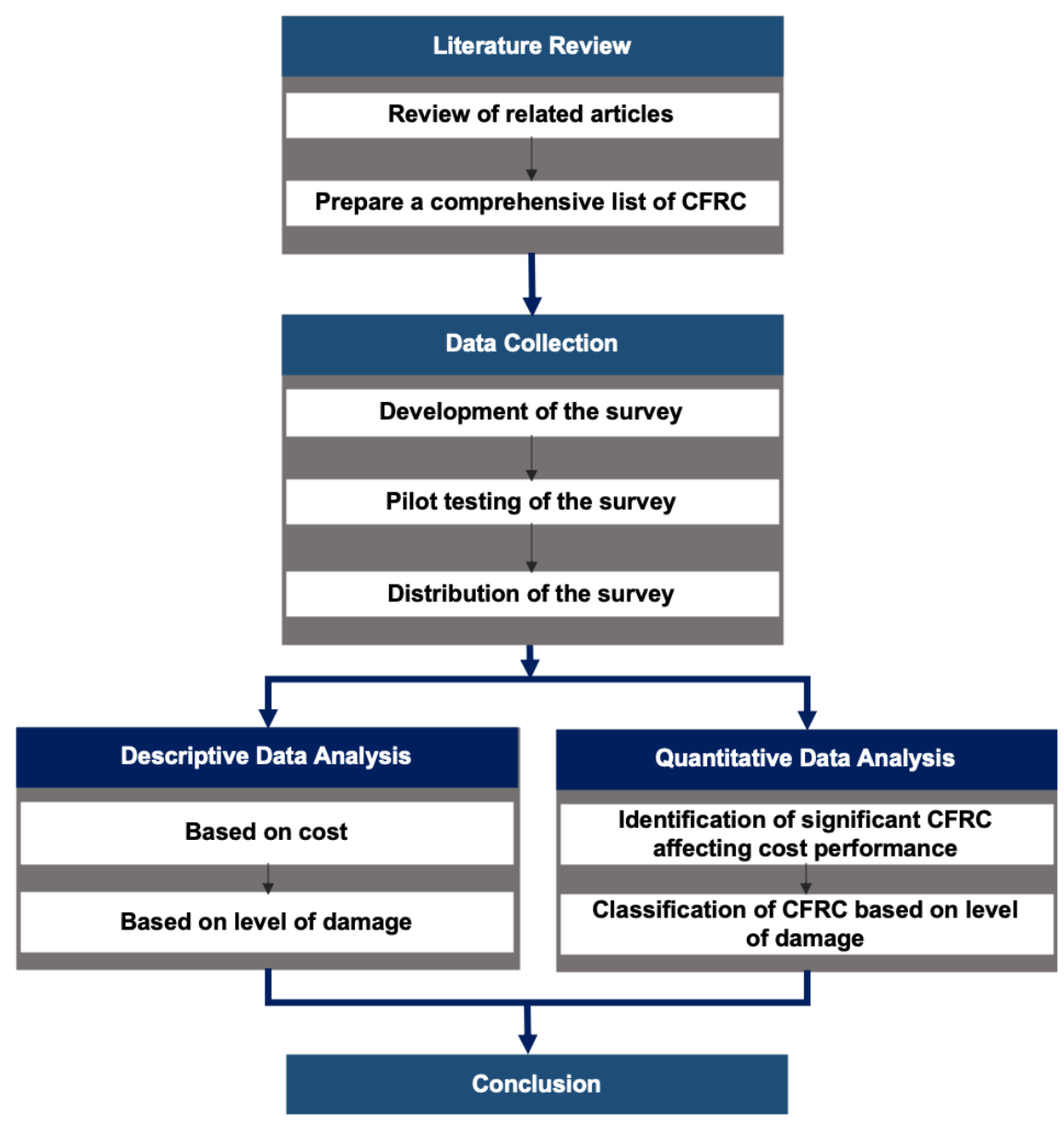

Fig. 1. Research methodology

Each CFRC was converted to a question of a survey that was pilot tested and distributed. The survey responses were analysed descriptively and quantitively and were discussed and interpreted to identify and classify the CFRCs that affect the cost of reconstruction after a disaster.

\subsection{Statistical analysis methods}

Various statistical tests were utilized, depending on the type of data that was collected from the survey. Table 2 summarizes the basic formal statistical methods that were used for the quantitative analysis in this study. The P-values that indicated the statistical significance of differences between the two targeted groups were generated through the relevant tests. 
Table 2. Statistical analysis methods

\begin{tabular}{ll}
\hline \multicolumn{1}{c}{ Statistical Test } & \multicolumn{1}{c}{ Assumptions } \\
\hline $\begin{array}{l}\text { Two-sample } t \text {-test: This test was used for responses of a count or } \\
\text { numerical value. }\end{array}$ & $\begin{array}{l}\bullet \text { The two groups follow a normal distribution. } \\
\text { Each project was independent from other projects. }\end{array}$ \\
\hline $\begin{array}{l}\text { Kruskal-Wallis: This test was used for Likert-scale questions (ordinal } \\
\text { seven-point scale), where it could not be assumed that the data }\end{array}$ & $\begin{array}{l}\bullet \text { Each project was independent from other projects. } \\
\text { followed a normal distribution. }\end{array}$ \\
\hline $\begin{array}{l}\text { Chi-squared test: This test was used for survey questions with binary } \\
\text { responses ("Yes" or "No"), testing whether the observed frequencies } \\
\text { of "Yes" or "No" are equal for both targeted groups. }\end{array}$ & \\
\hline
\end{tabular}

\section{Data collection}

\subsection{Potential PDR listing}

A comprehensive literature review of scholarly articles was conducted for this study. A list of 30 potential CFRCs was prepared, based on the findings of the study and the authors' understanding and expertise. Table 3 shows the CFRCs that were considered for this study.

Table 3. List of potential CFRCs

\begin{tabular}{|c|c|c|c|}
\hline \# & List of CFRCs & \# & List of CFRCs \\
\hline CFRC1 & Number of main/truck lines & CFRC16 & Quality issues of materials \\
\hline CFRC2 & Total length & CFRC17 & Quality issues of equipment \\
\hline CFRC3 & Level of complexity & CFRC18 & Frequency level of logistics/ management issues \\
\hline CFRC4 & Distance from highly populated area & CFRC19 & Quality of on-site inspection \\
\hline CFRC5 & Level of damage & CFRC20 & Frequency of on-site inspection \\
\hline CFRC6 & Level of traffic disturbance & CFRC21 & Information management \\
\hline CFRC7 & Shortage of experts & CFRC22 & Pace of decision-making process \\
\hline CFRC8 & Shortage of field laborers & CFRC23 & Implementation level of risk management \\
\hline CFRC9 & Productivity level of contractors & CFRC24 & Coordination \\
\hline CFRC10 & Shortage of materials & CFRC25 & Pace of workers' mobilization \\
\hline CFRC11 & PRT11. Shortage of equipment & CFRC26 & Volume of debris \\
\hline CFRC12 & PRT12. Inflation of labor wages & CFRC27 & $\begin{array}{l}\text { Environmental/safety issues prior to executing the } \\
\text { project }\end{array}$ \\
\hline CFRC13 & PRT13. Availability level of on-site infrastructure & CFRC28 & Work suspension through execution of the project \\
\hline CFRC14 & PRT14. On-site accommodation level for staff & CFRC29 & Regulatory requirements \\
\hline CFRC15 & PRT15. Shortage of suppliers & CFRC30 & Availability of required temporary pathways \\
\hline
\end{tabular}




\subsection{Survey development}

Based on the identified potential PRTs, a structured survey was developed, and each PRT became one question in the survey. The survey consisted of three main parts: i) respondent information, ii) area transportation network, and iii) project-based information. The survey consisted of 46 questions, and two samples of the questions are presented in Figure 2.

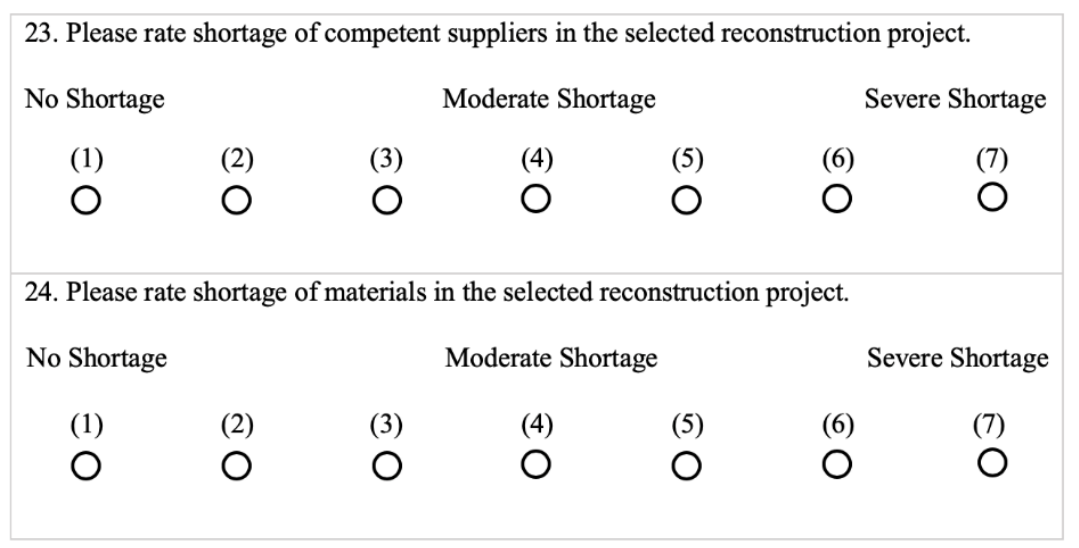

Fig. 2. Research methodology

\subsection{Pilot testing}

After the survey was developed, it was pilot tested to verify its suitability for the respondents. The pilot testing was performed among a limited number of respondents and was modified according to their comments. After that, the necessary approval for the survey was acquired and the survey was finalized.

\subsection{Survey distribution and collection}

A list of 500 potential respondents was prepared by the team. The list consisted of the name and contact information of the potential respondents who were either policymakers, project managers, or design and construction engineers, etc. Special attention was given to ensure that the respondents were working in different governmental and private agencies such as state transportation agencies, departments of transportation, the offices of cities, etc. They were contacted by email, and after three follow-up emails, 30 responses were collected.

\section{Descriptive analysis}

\subsection{Analysis based on project cost}

The descriptive data from the analyses associated with the baseline and actual budgets and schedules, as well as the rework costs corresponding to the 30 reconstruction projects, are provided in Table 4. As illustrated in this table, the means of the baseline and actual budgets were roughly $\$ 25$ million and $\$ 35$ million, respectively.

Table 4. Descriptive data analysis based on cost

\begin{tabular}{cccccc}
\hline & & Minimum & Mean & Maximum & Standard Deviation \\
\hline \multirow{2}{*}{ Cost } & Baseline Budget & $\$ 300 \mathrm{~K}$ & $\$ 22,930 \mathrm{~K}$ & $\$ 100,000 \mathrm{~K}$ & $\$ 33,200 \mathrm{~K}$ \\
& & & & & \\
& Actual Cost & $\$ 500 \mathrm{~K}$ & $\$ 36,540 \mathrm{~K}$ & $\$ 150,000 \mathrm{~K}$ & $\$ 53,110 \mathrm{~K}$ \\
\hline
\end{tabular}

\subsection{Analysis based on the level of damage}

The respondents were asked to provide information about the damage level of the affective transportation infrastructures resulting from a hurricane in which they were involved. The results are shown in Figure 3. 


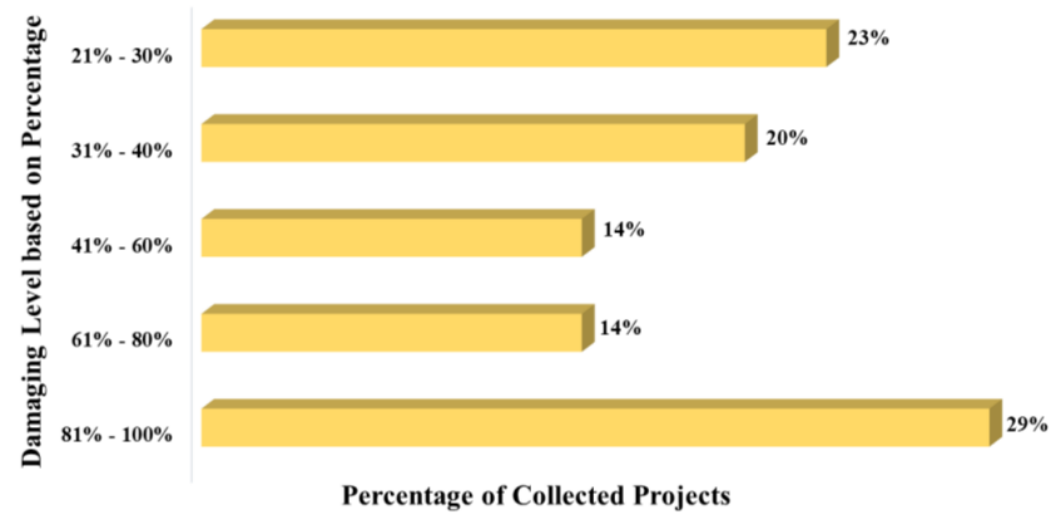

Fig. 3. Damage level of disasters based on the percentage

Figure 3 illustrates that about $45 \%$ of hurricanes damaged more than $60 \%$ of the transportation systems. In addition, roughly $35 \%$ of the transportation systems were damaged from $30 \%$ to $60 \%$. As presented in Figure 5, the minimum damage level of transportation infrastructures was $21 \%$.

\section{Quantitative analysis}

\subsection{Significant CFRCS affecting the overall cost of reconstruction projects}

The P-Values corresponding to the significant CFRCs affecting the cost performance of reconstruction projects are shown in Table 5.

Table 5. Significant CFRCs affecting cost performance

\begin{tabular}{|c|c|c|}
\hline Category & List of CFRCs & $P$-Value \\
\hline & CFRC1. Number of main/truck lines & $0.051^{*}$ \\
\hline Physical & CFRC2. Total length & $0.049^{* *}$ \\
\hline \multirow[t]{2}{*}{ Characteristics } & CFRC3. Level of complexity & $0.036^{* *}$ \\
\hline & CFRC4. Distance from highly populated area & $0.078^{*}$ \\
\hline \multirow{6}{*}{$\begin{array}{l}\text { Damaging } \\
\text { Level }\end{array}$} & CFRC5. Level of damage & $0.044^{* *}$ \\
\hline & CFRC6. Level of traffic disturbance & 0.196 \\
\hline & CFRC7. Shortage of experts & $0.011^{*}$ \\
\hline & CFRC8. Shortage of field laborers & $0.054^{* *}$ \\
\hline & CFRC9. Productivity level of contractors & $0.069^{*}$ \\
\hline & CFRC10. Shortage of materials & $0.077^{*}$ \\
\hline \multirow[t]{5}{*}{ Resource } & CFRC11. Shortage of equipment & $0.017^{* *}$ \\
\hline & CFRC12. Inflation of labor wages & $0.096^{*}$ \\
\hline & CFRC13. Availability level of on-site infrastructure & $0.080^{*}$ \\
\hline & CFRC14. On-site accommodation level for staff & 0.350 \\
\hline & CFRC15. Shortage of supplier & $0.065^{*}$ \\
\hline \multirow{2}{*}{ Quality } & CFRC16. Quality issues of materials & $0.018^{\star *}$ \\
\hline & CFRC17. Quality issues of equipment & $0.011^{* *}$ \\
\hline \multirow{8}{*}{$\begin{array}{c}\text { Project } \\
\text { Management }\end{array}$} & CFRC18. Frequency level of logistics/management issues & $0.013^{* *}$ \\
\hline & CFRC19. Quality of on-site inspection & $0.072^{*}$ \\
\hline & CFRC20. Frequency of on-site inspection & 0.422 \\
\hline & CFRC21. Information management & $0.045^{*}$ \\
\hline & CFRC22. Pace of decision-making process & $0.020^{* *}$ \\
\hline & CFRC23. Implementation level of risk management & $0.012^{\star *}$ \\
\hline & CFRC24. Coordination & $0.046^{* *}$ \\
\hline & CFRC25. Pace of workers' mobilization & 0.258 \\
\hline Environment & CFRC26. Volume of debris & $0.082^{*}$ \\
\hline$\&$ & CFRC27. Environmental/safety issues prior to execution of the project & $0.033^{\star *}$ \\
\hline Safety & CFRC28. Work suspension through execution of the project & $0.060^{*}$ \\
\hline Legal & CFRC29. Regulatory requirement & 0.205 \\
\hline Local & CFRC30. Availability of required temporary pathways & 0.163 \\
\hline
\end{tabular}

** denotes significant differences with 95\% confidence

* denotes significant differences with $90 \%$ confidence 
As there were three types of data (continuous, seven-point Likert scale, and binary) collected from the survey, the two-sample t-test, Kruskal-Wallis, and Chi-squared test were performed. As presented in Table 5, the 30 CFRCs identified by the literature were classified into eight categories: (1) physical characteristics, (2) damage level, (3) resources, (4) quality, (5) project management, (6) environment and safety, (7) legal, and (8) local. Table 5 presents that 24 out of 30 identified CFRCs were determined statistically significant for the cost performance of the targeted projects.

CFRC-3 (level of complexity), which belongs to the category of project characteristics, is an indicator that if a reconstruction project is complex, an increasing number of reworks is more probable due to errors made because of deficiencies in the laborers' knowledge and/or experience. Ultimately, these reworks might increase the cost of reconstruction. Since financial limitations are common after a disaster, the stated CFRC significantly decreases the cost performance.

Table 5 presents that low-quality materials (CFRC-16), belonging to the category of quality, and low quality of equipment (CFRC-17), belonging to the category of quality, lead to their replacement during the reconstruction process, which causes serious shortages in materials and equipment and increases the number and cost of overruns.

\subsection{Classification of CFRCs affecting cost performance of low and high damage levels}

The results of the P-Values of the CFRCs that affect the cost performance of infrastructures damaged at different levels is shown in Table 6 . Twenty-six (26) CFRCs were determined statistically significant for highly damaged reconstruction projects and 19 CFRCs were recorded as statistically significant for low-level damaged reconstruction projects.

Table 6 indicates that when the damage is greater, more attention must be given to the factors that affect reconstruction cost. For example, when the level of damage is low, the level of complexity (CFRC 3 ) is less. and this CFRC does not affect the cost of reconstruction. However, when the level of damage is high, the complexity of the reconstruction is also probably high and creates the possibility of reworks and resulting overruns. Similarly, the level of traffic overruns (CFRC 6) is a significant factor for high-damage reconstruction costs but not a significant factor of low-damage reconstruction work.

Table 6. Significant CFRCs affecting cost performance of low and high damage transportation infrastructure

\begin{tabular}{|c|c|c|c|}
\hline \multirow{3}{*}{ Category } & \multirow{3}{*}{ List of CFRCs } & \multicolumn{2}{|c|}{$P$-Value } \\
\hline & & Highly & Low Level \\
\hline & & Damaged & Damaged \\
\hline & CFRC1. Number of main/truck lines & $0.040^{* \star}$ & $0.022^{* *}$ \\
\hline Physical & CFRC2. Total length & $0.025^{\star *}$ & $0.034^{* *}$ \\
\hline \multirow[t]{2}{*}{ Characteristics } & CFRC3. Level of complexity & $0.068^{*}$ & 0.534 \\
\hline & CFRC4. Distance from highly populated area & $0.056^{*}$ & $0.036^{*}$ \\
\hline \multirow{3}{*}{$\begin{array}{c}\text { Damage } \\
\text { Level }\end{array}$} & CFRC6. Level of traffic disturbance & $0.011^{\star *}$ & 0.397 \\
\hline & CFRC7. Shortage of experts & $0.001^{* *}$ & $0.017^{* *}$ \\
\hline & CFRC8. Shortage of field laborers & $0.022^{* *}$ & $0.075^{\star}$ \\
\hline \multirow[t]{3}{*}{ Resource } & CFRC9. Productivity level of contractors & $0.078^{*}$ & $0.041^{* *}$ \\
\hline & CFRC10. Shortage of materials & $0.081^{*}$ & $0.082^{*}$ \\
\hline & CFRC11. Shortage of equipment & $0.065^{*}$ & $0.037^{* *}$ \\
\hline
\end{tabular}




\begin{tabular}{|c|c|c|c|}
\hline & CFRC12. Inflation of labor wages & $0.055^{*}$ & $0.031^{* *}$ \\
\hline & CFRC13. Availability level of on-site infrastructure & $0.063^{*}$ & $0.061^{*}$ \\
\hline & CFRC14. On-site accommodation level for staff & 0.325 & 0.197 \\
\hline & CFRC15. Shortage of suppliers & $0.035^{\star \star}$ & 0.487 \\
\hline \multirow{2}{*}{ Quality } & CFRC16. Quality issues of materials & $0.012^{* *}$ & $0.059^{*}$ \\
\hline & CFRC17. Quality issues of equipment & $0.062^{*}$ & $0.085^{*}$ \\
\hline \multirow{8}{*}{ Management } & CFRC18. Frequency level of logistics/management issues & $0.010^{\star *}$ & $0.063^{*}$ \\
\hline & CFRC19. Quality of on-site inspection & $0.078^{*}$ & $0.021^{\star *}$ \\
\hline & CFRC20. Frequency of on-site inspection & $0.085^{\star}$ & 0.258 \\
\hline & CFRC21. Information management & $0.058^{*}$ & $0.089^{*}$ \\
\hline & CFRC22. Pace of decision-making process & $0.071^{*}$ & $0.073^{*}$ \\
\hline & CFRC23. Implementation level of risk management & $0.008^{* *}$ & $0.014^{* *}$ \\
\hline & CFRC24. Coordination & $0.001^{\star *}$ & $0.051^{*}$ \\
\hline & CFRC25. Pace of workers' mobilization & $0.061^{*}$ & 0.357 \\
\hline Environment & CFRC26. Volume of debris & $0.044^{\star *}$ & 0.526 \\
\hline \& & CFRC27. Environmental/safety issues prior to execution of the project & $0.055^{\star}$ & $0.070^{*}$ \\
\hline Safety & CFRC28. Work suspension through execution of the project & $0.091^{*}$ & 0.357 \\
\hline Legal & CFRC29. Regulatory requirement & 0.258 & 0.278 \\
\hline Local & CFRC30. Availability of required temporary pathways & 0.195 & 0.355 \\
\hline
\end{tabular}

\section{Conclusion}

The intensity and destructive nature of natural disasters are gradually and constantly increasing, and with them, the need for reconstruction of infrastructure, including transportation infrastructure, is also increasing. Keeping the reconstruction cost within budget is almost always a priority for practitioners, yet it is often difficult to do. This study identified the factors that contribute to the reconstruction cost of transportation infrastructure after a disaster. A survey was conducted that incorporated the identified factors, and the responses were descriptively and quantitatively analyzed. It was found that effective coordination plays a critical role in completing a project within the allocated budget. Additionally, it was found that a slow decision-making process commonly causes delays in the reconstruction that increase the probability of cost overruns. Moreover, the reconstruction of transportation infrastructures with a high level of damage depends on more factors than those with a low level of damage. The outcomes of this paper will be of value to authorities who are responsible for controlling budget overruns during a postdisaster reconstruction project.

\section{References}

[1] S. Fuchs. "Against essentialism: A theory of culture and society." Cambridge, MA: Harvard University Press, 2009.

[2] [2] M.S. Eid, I.H. El-adaway. "Integrating the social vulnerability of host communities and the objective functions of associated stakeholders during disaster recovery processes using agent-based modeling". Journal of Computing in Civil Engineering, 31(5): 04017030, 2017. https://doi.org/10.1061/(ASCE)CP.1943-5487.0000680

[3] Kermanshachi, S.; Bergstrand, K.; Rouhanizadeh, B. "Identifying, weighting and causality modeling of social and economic barriers to rapid infrastructure recovery from natural disasters: A study of hurricanes Harvey, Irma and Maria". Technical report, 2019.

[4] G.R. Webb, K.J. Tierney, J.M. Dahlhamer. "Predicting long-term business recovery from disaster: a comparison of the Loma Prieta earthquake and Hurricane Andrew, Glob. Environ. Change Part B: Environ." Hazards, 4, 45-58, 2002. https://doi.org/10.3763/ehaz.2002.0405 
[5] A. Josephson, H. Schrank, M. Marshall. "Assessing preparedness of small businesses for hurricane disasters: Analysis of pre-disaster owner, business and location characteristics." International Journal of Disaster Risk Reduction, 23, 25-35, 2017. https://doi.org/10.1016/j.ijdrr.2017.03.013

[6] M. Careem, C. De Silva, R. De Silva, L. Raschid, S. Weerawarana. "Overview of a disaster management system." International Conference on Information and Automation, Dec. 15-17, 2006. https://doi.org/10.1109/ICINFA.2006.374152

[7] J.S. Picou, B.K. Marshall. "Katrina as a paradigm shift: Reflections on disaster research in the twenty-first century". The sociology of Katrina: Perspectives on a modern catastrophe, 1-20, 2007.

[8] H.B. Ku, Y.N. Ma. "Rural-urban alliance as a new model for post-disaster social work intervention in community reconstruction: The case in Sichuan, China." International Social Work, 58(5):743-758, 2015. https://doi.org/10.1177/0020872815583073

[9] Rouhanizadeh, B.; Kermanshachi, S.; Dhamangaonkar, V. "Identification and categorization of policy and legal barriers to long-term timely post-disaster reconstruction". Journal of Legal Affairs and Dispute Resolution in Engineering and Construction, Volume 11 issue 3, 2019. https://doi.org/10.1061/(asce)la.1943-4170.0000307

[10] M.C. Comerio. "Estimating downtime in loss modeling." Earthquake Spectra, 22(2), 349-365, 2006. https://doi.org/10.1193/1.2191017

[11] P.K. Freeman. "Allocation of post-disaster reconstruction financing to housing." Building Research \& Information, 32(5), 37-41, 2007. https://doi.org/10.1080/0961321042000221016

[12] Rouhanizadeh, B.; Kermanshachi, S. "Comparative analysis of public's and decision-maker's perspectives on socioeconomic barriers causing delay in post-disaster recovery processes". ASCE Construction Research Congress (CRC), 2019.

[13] Safapour, E.; Kermanshachi, S. "Identification and categorization of factors affecting duration of post-disaster reconstruction of interdependent transportation systems". ASCE Construction Research Congress (CRC), 2019.

[14] Hidayat, C. Egbu. "A literature review of the role of project management in post-disaster reconstruction." Proceedings of $26^{\text {th }}$ Annual ARCOM Conference, Association of Researchers in Construction Management, Leeds, 2010.

[15] Y. Chang, S. Wilkinson, D. Brunsdon. "An integrated approach: managing resources for post-disaster reconstruction." Disasters, 35(4), 739-65, 2011. https://doi.org/10.1111/j.1467-7717.2011.01240.x

[16] Pamidimukkala A, Kermanshachi S, Kartick S. "Impact of Natural Disasters on Construction Projects: Strategies to Prevent Cost and Schedule Overruns in Reconstruction projects". Creative Construction Conference (CCC), 2020.

[17] Rouhanizadeh, B.; Kermanshachi, S.; Dhamangaonkar, V. "Reconstruction of critical and interdependent infrastructures due to catastrophic natural disasters: lessons learned". ASCE Construction Research Congress, 2019.

[18] Safapour, E., Kermanshachi, S., Nipa, T.J. Schedule Performance Analysis of Infrastructure Reconstruction Projects Due to Extreme Events. Creative Construction Conference (CCC), 2020.

[19] Safapour, E., Kermanshachi, S., Nipa, T.J. A Damage-based Analysis of Rework in Reconstruction of Infrastructure Projects Due to Natural Disasters. Creative Construction Conference (CCC), 2020.

[20] F.J. Bromilow, M.F. Hinds, N.F. Moody. "AIQS survey of building contract time performance." Build. Econ., 19(4), 223-229, 1980.

[21] Kermanshachi, S., \& Rouhanizadeh, B. "Feasibility analysis of post disaster reconstruction alternatives using automated BIM-based construction cost estimation tool". In Proceeding of CSCE 6th International Disaster Mitigation Specialty Conference, Montreal: Canadian Society of Civil Engineering, pp. 13-16. 2018.

[22] Pamidimukkala A, Kermanshachi S, Safapour E. Challenges in Post-Disaster Housing Reconstruction: Analysis of Urban Vs. Rural Communities". Creative Construction Conference (CCC), 2020

[23] M. Mojtahedi, S. Newton, J. Von Meding. "Predicting the resilience of transport infrastructure to a natural disaster using Cox's proportional hazards regression model." Natural Hazards, 85(2), 1119-1133, 2017. https://doi.org/10.1007/s11069-016-2624-2.

[24] Rouhanizadeh, B.; Kermanshachi, S.; Nipa, T. J. "Identification, categorization, and weighting of barriers to timely post-disaster recovery process". ASCE International Conference on Computing in Civil Engineering, 2019. Olsen, A. H., \& Porter, K. A. "What We Know about demand surge: Brief summary". Natural Hazards Review, 12(2), 62-71, 2011. https://doi.org/10.1061/(ASCE)NH.15276996.0000028

[25] Rouhanizadeh, B., \& Kermanshachi, S. "Investigating the Relationships of Socioeconomic Factors Delaying Post-Disaster Reconstruction". In Proceedings of ASCE International Conference on Computing in Civil Engineering, pp. 17-19. 2019. https://doi.org/10.1061/9780784482445.005

[26] Nipa T, J., Kermanshachi, S. Identification of the Resilience Dimensions and Determination of their Relationships in Critical Transportation Infrastructures. ASCE Construction Research Congress (CRC), 2019

[27] E. Hayat, R.D.G. Amaratunga. "Road reconstruction in post-disaster recovery; the challenges and obstacles". In: International conference on Building Resiliene, 2011.

[28] Rouhanizadeh, B.; Kermanshachi, S. "Gender-based evaluation of physical, social, and economic challenges in natural disasters management". ASCE Construction Research Congress (CRC), 2019

[29] Rouhanizadeh, B.; Kermanshachi, S. "A Systematic Approach to Analysis and Prioritization of the Socioeconomic Policies and Legal barriers to Rapid Post Disaster Reconstruction". 7th CSCE International Construction Specialty Conference (ICSC), 2019

[30] Rose, C.K. Huyck. "Improving catastrophe modeling for business interruption insurance needs." Risk Analysis, 36(10), 1896-1915, 2016. https://doi.org/10.1111/risa.12550

[31] A.K. Jha, J.E. Duyne. "Safer homes, stronger communities: a handbook for reconstructing after natural disasters." World Bank Publications, 2010. https://doi.org/10.1596/978-0-8213-8045-1

[32] Nipa T, J., Kermanshachi, S., Ramaji I, J. Comparative analysis of strengths and limitations of infrastructure resilience measurement methods. $7^{\text {th }}$ CSCE International Construction Speciality Conference (ICSC), 2019

[33] Kermanshachi, s. "Decision making and uncertainity analysis in success of construction projects". Ph.D. Dissertation, Texas A \& M University, 2016.

[34] J. Odeck. "Cost overruns in road construction-what are their sizes and determinants?". Transport Policy, 11, 43-53, 2004. https://doi.org/10.1016/S0967-070X(03)00017-9

[35] P. Wichan, R. Thammasak, S. Vanee, S. "Forecasting final budget and duration of highway construction projects." Engineering, Construction and Architectural Management, 16, 544-557, 2009. https://doi.org/10.1108/09699980911002566

[36] Kaliba, M. Muya, M., K. Mumba. "Cost escalation and schedule delays in road construction projects in Zambia." International Journal of Project Management, 27, 522-531, 2009. https://doi.org/10.1016/j.jproman.2008.07.003

[37] Kermanshachi ,S., Dao B, Shane J, Anderson S. "An emperical study into identifying project complexity management strategies". Procedia Engineering, 145, 603-610, 2016. https://doi.org/10.1016/j.proeng.2016.04.050

[38] Kermanshachi ,S., Dao B, Shane J, Anderson S. "Project complexity indicators and management strategies-a Delphi study". Procedia Engineering, 145, 587-594, 2016. https://doi.org/10.1016/j.proeng.2016.04.048 
Proceedings of the Creative Construction e-Conference (2020) 053

Available online at e-2020.creative-construction-conference.com/proceedings/

[39] S.U.R. Toor, S.O. Ogunlana. "Critical COMs of success in large-scale construction projects: Evidence from Thailand construction industry." International Journal of Project Management, 26(4), 420-430, 2008. https://doi.org/10.1016/j.ijproman.2007.08.003

[40] Safapour, E., Kermanshachi, S. „Investigation of the Challenges and Their Best Practices for Post-Disaster Reconstruction Safety: Educational Approach for Construction Hazards". Transportation Research Board 99th Annual Conference, 2019

[41] A. Moloney, "Haitians still homeless "suffering in despair" 4 years after quake - Amnesty." Thomson Reuters Foundation, 4-6, 2014. 